\title{
Clinical implications of Ezrin and CD44 co-expression in breast cancer
}

\author{
LIFANG MA $^{1}$ and TAO JIANG ${ }^{2}$ \\ Departments of ${ }^{1}$ Geriatrics and ${ }^{2}$ General Surgery, The First Affiliated Hospital \\ of Harbin Medical University, Harbin 150001, P.R. China
}

Received May 18, 2013; Accepted July 5, 2013

DOI: 10.3892/or.2013.2641

\begin{abstract}
The aim of the present study was to investigate the expression status and clinical implications of the stem cell genes Ezrin and CD44 in breast cancers. Expression of the Ezrin protein in $\mathrm{CD} 44^{+} / \mathrm{CD} 24^{- \text {llow }}$ tumor cells (CSCs) was detected by western blotting. The resulting expression status and the relationship between Ezrin and CD44 were determined in 726 breast cancers using immunohistochemistry staining and immunofluorescence double staining. Subsequently, the relationship between Ezrin and CD44 protein co-expression and clinicopathological parameters and prognosis was determined. The Ezrin protein was expressed at a higher level in CSCs when compared to that in the control cells and was related to the resistance of CSCs to chemotherapy. The Ezrin and CD44 proteins were co-expressed in the co-immunoprecipitation (Co-IP) test. Ezrin and CD44 co-expression was observed in 235 (32.37\%) of the 726 cases examined. After universal analysis and multivariate analysis, histological type, lymph node metastasis, triple-negative breast cancer, TNM stage and distant metastasis were verified as related to Ezrin and CD44 co-expression $(\mathrm{P}=0.011,0.006,0.001,0.011$ and 0.001 , respectively). A survival analysis revealed that Ezrin and CD44 co-expression was associated with a poorer prognosis (36.91 vs. $81.54 \%, \mathrm{P}=0.001$ ). After running Cox regression, the factors of age, tumor size, lymph node metastasis, triple-negative tumor status, TNM stage, distant metastasis and Ezrin and CD44 co-expression were shown to be independent prognostic factors of breast cancer. The co-expression of Ezrin and CD44 may be a new biomarker for evaluating the progression and chemotherapy sensitivity of breast cancer.
\end{abstract}

\section{Introduction}

Breast cancer is the most common type of malignancy in women and is the second leading cause of cancer-related

Correspondence to: Professor Lifang Ma, Department of Geriatrics, The First Affiliated Hospital of Harbin Medical University, Harbin 150001, P.R. China

E-mail: malifanghayida@163.com

Key words: breast cancer, stem cells, Ezrin, CD44, chemotherapy resistance, survival mortality in women worldwide (1). Although a variety of therapeutic strategies have been developed to fight breast cancers in recent years, more than $40 \%$ of patients with breast cancer experience tumor recurrence after comprehensive antitumor treatments (2). Breast cancer stem cells are a small group of tumor cells with the capacity to self-renew and a strong ability to form solid breast tumors. This small group of tumor cells can also differentiate to a relatively quiescent primitive group of cancer cells that are considered the underlying factor for tumor recurrence and the main reason breast cancers resist therapy $(3,4)$.

With a better understanding of cancer stem cell theory, stem cell-related genes in malignant tumors have gained increased research attention. In 2003, Al-Hajj et al (5) identified and isolated tumorigenic cells named $\mathrm{CD} 44^{+} / \mathrm{CD} 24^{- \text {/low/Lineage }}$ in 8 of 9 patients using a model in which human breast cancer cells were grown in immunocompromised mice. CD44 is a cell-surface glycoprotein involved in cell-cell interactions, cell adhesion, and migration and has been considered to be a promising potential target that may lead to more effective therapies (6).

Recent studies have reported that Ezrin may be a prognostic factor and may predict potential lung metastasis in osteosarcoma and could also possibly be used as a new therapeutic target $(7,8)$. Boldrini et al (9) reported, however, that neither CD44 nor Ezrin immunoexpression predicts the prognosis of patients with osteosarcoma. Data from in vitro experiments revealed the direct molecular interactions of Ezrin with molecules related to metastatic functions such as CD44, merlin and Lamp-1. This is consistent with its role in forming phagocytic vacuoles, vesicular sorting, and the migration capacities of melanoma cells. Currently, the relationship between Ezrin and CD44 expression in breast cancer and the clinical implications in breast cancer are still unclear. In the present study, we sorted and identified breast cancer stem cells (CSCs) and investigated the expression status of Ezrin and CD44 in breast CSCs. We then examined the clinical implications of our inquiry in breast cancer in order to lay a foundation for managing breast cancer.

\section{Materials and methods}

Patients and tissue specimens. A total of 726 patients with histologically confirmed breast cancer who underwent radical 
operations at the First Affiliated Hospital of Harbin Medical University, between January 2001 and January 2006 were enrolled for immunohistochemical and immunofluorescence double staining and prognostic analysis. The First Affiliated Hospital of Harbin Medical University approved the study protocol.

Cell culture and separation of CSCs from non-stem cancer cells (NSCCs). Breast cancer cell line MDA-MB-231 was grown in Dulbecco's modified Eagle's medium (DMEM), $10 \%$ fetal bovine serum (FBS), and penicillin-streptomycin. To separate CSCs from NSCCs, flow cytometric cell sorting was performed on single-cell suspensions that were stained with the CD44 antibody (FITC-conjugated) (555478) and with the CD24 antibody (PE-conjugated) (555428) (both from BD Biosciences, Franklin Lakes, NJ, USA). As used throughout this study, CSCs are defined by the minority CD $44^{\text {high }} / \mathrm{CD} 24^{\text {low }}$ population, whereas NSCCs are defined by the majority CD $44^{\text {low }} / \mathrm{CD} 24^{\text {high }}$. Mammospheres were generated by placing CSCs in suspension $(1,000$ cells $/ \mathrm{ml})$ in serum-free DMEM/F12 media, supplemented with B27 (1:50; Invitrogen Life Technologies), 0.4\% BSA, $20 \mathrm{ng} / \mathrm{ml} \mathrm{EGF,} \mathrm{and} 4 \mathrm{mg} / \mathrm{ml}$ insulin (10). After 6 days of incubation, mammospheres were typically $>75 \mathrm{mM}$ in size with $\sim 97 \%$ being $\mathrm{CD} 44^{\text {high }} / \mathrm{CD} 24^{\text {low }}$. For serial passaging, 6-day-old mammospheres were harvested using a $70-\mu \mathrm{m}$ cell strainer, whereupon they were dissociated to single cells with trypsin, and then regrown in suspension for 6 days.

Cell transfection. For siRNA experiments, CSCs or 6-day-old mammospheres were transfected with $100 \mathrm{nM}$ of siRNAs (Ambion, Inc.) against Ezrin, and negative control (AM4611), using siPORT NeoFX transfection agent. The resulting cells were assayed 24 or $48 \mathrm{~h}$ post transfection.

Treatments with chemotherapeutic agents and assessment of cell viability. The sensitivities of the above cells to three chemotherapeutic drugs were examined using the Cell Counting Kit-8 (CCK-8) technique. Cells were plated at a density of $5 \times 10^{4} / \mathrm{ml}$ cells/well into ultra-low adhering 96-well plates containing $100 \mu \mathrm{l}$ Complete MammoCult medium and treated with concentrations of cisplatin (DDP), epirubicin (EPI) and docetaxel (DTX) as follows: 0, 0.05, 0.1, 0.25, 0.3, 0.35 and $0.4 \mathrm{mM}$. Forty-eight hours after treatment, CCK-8 reagent was added to each well and incubated for $2 \mathrm{~h}$ before reading at a wavelength of $450 \mathrm{~nm}$.

Co-immunoprecipitation and western blotting. Cell lysate preparation, immunoprecipitation, and western blotting were performed as described previously (11). For inhibition of proteasomal degradation, cells were treated with $10 \mu \mathrm{M}$ of MG132 (Sigma-Aldrich, St. Louis, MO, USA) for 4 h. Briefly, cells were lysed with a buffer of $0.1 \% \mathrm{SDS}, 50 \mathrm{mmol} / 1 \mathrm{Tris}-\mathrm{HCl}$ ( $\mathrm{pH} 7.6$ ), 1\% NP-40, $150 \mathrm{mmol} / 1 \mathrm{NaCl}, 2 \mathrm{mg} / \mathrm{ml}$ aprotinin, $2 \mathrm{mg} / \mathrm{ml}$ leupeptin and $7 \mathrm{mg} / \mathrm{ml}$ PMSF. Protein concentrations were determined using the BCA protein assay kit (Pierce Biotechnology, Inc., Rockford, IL, USA). Thirty micrograms of protein was separated on $10 \%$ SDS-PAGE gels and transferred to a PVDF membrane. After blocking, the membrane was incubated with the primary antibody at $4^{\circ} \mathrm{C}$ overnight
(Ezrin, ab40839; CD44, ab51037; Abcam). After washing, the membrane was incubated with a secondary antibody at a dilution 1:2,000 at room temperature for $1 \mathrm{~h}$. Proteins were detected using an ECL kit (Varsal Instruments, Beijing, China), and anti- $\beta$-actin antibody (Sigma-Aldrich) was used as the loading control. Densitometry was performed by Gel-Pro Analyzer software (Media Cybernetics, Silver Spring, MD, USA).

Immunohistochemistry experimental procedures. Thin slices of tumor tissue from all cases received at our histopathology unit were fixed in $4 \%$ formaldehyde solution ( $\mathrm{pH} 7.0$ ) for periods not exceeding $24 \mathrm{~h}$. The tissues were processed routinely for paraffin embedding, and 4- $\mu \mathrm{m}$ sections were cut and placed on glass slides coated with (3-aminopropyl)-triethoxysilane for immunohistochemistry. Tissue samples were stained with hematoxylin and eosin to determine the histological type and the grade of the tumors.

Briefly, breast tumor tissues were cut at a thickness of $4 \mu \mathrm{m}$ using a cryostat. The sections were mounted on microscope slides, air-dried, and then fixed in a mixture of $50 \%$ acetone and $50 \%$ methanol. The sections were then de-waxed with xylene, gradually hydrated with gradient alcohol, and washed with PBS. Sections were incubated for $60 \mathrm{~min}$ with the primary antibody (Ezrin, ab40839; CD44, ab51037). Following washings with PBS, sections were incubated for $30 \mathrm{~min}$ in the secondary biotinylated antibody (Multilink swine anti-goat/mouse/rabbit immunoglobulin; Dako, Inc.). Following washings, avidin-biotin complex (1:1,000 dilution; Vector Laboratories, Burlingame, CA, USA) was then applied to the sections for 30-60 min at room temperature. The immunoreactive products were visualized by catalysis of 3,3'-diaminobenzidine (DAB) using horseradish peroxidase in the presence of $\mathrm{H}_{2} \mathrm{O}_{2}$, following extensive washings. Sections were then counterstained in Gill's hematoxylin and dehydrated in ascending grades of methanol before clearing in xylene and mounting under a coverslip.

Evaluation of immunohistochemical reaction intensities. The intensities of the immunohistochemical reactions were estimated independently by 2 pathologists. In order to evaluate the expression of the proteins analyzed, a semi-quantitative scale of the immunoreactive score (IRS), with the authors' own modifications, was applied (12) in which the intensity of the color reaction (no reaction, 0 ; weak color reaction, 1 ; moderate intensity, 2; intense reaction, 3) and the percentage of positive cells (no positive cells, $0 ;<25 \%$ positive cells, $1 ; 25-50 \%$ positive cells, $2 ; 51-75 \%$ positive cells, $3 ;>75 \%$ positive cells, 4) were both taken into account. The final, integrated scores ranged from 0 to 12 . Cases with expression scores ranging between 0 and 2 in the IRS scale were considered negative.

Double immunofluorescence staining. Surgical resected breast cancer tissues were fixed and cut at a thickness of $4 \mu \mathrm{m}$. The specimens were stained with control IgG, mouse anti-human Ezrin (1:50 dilution), rabbit anti-human CD44 polyclonal antibodies (1:50 dilution) (both from BD Biosciences) at $4^{\circ} \mathrm{C}$ for $12 \mathrm{~h}$. After being washed, the cells were incubated with biotinylated goat anti-mouse IgG secondary antibodies (1:1,000 dilution) in PBS for $30 \mathrm{~min}$ at room temperature. The 
bound antibodies were detected with PE and FITC, followed by mounting with DAPI medium (Vector Laboratories). The expression of CD44 and Ezrin was examined under a fluorescence microscope. The cell staining was observed under fluorescence microscopy.

Statistical analysis. All data were analyzed with SPSS Statistics software (version 13.0; Chicago, IL, USA). The relationships between Ezrin and other parameters were studied using the Chi-square test, Fisher's exact test, or independent t-tests. Disease-specific survival was analyzed using the Kaplan-Meier method. The log-rank test was used to analyze differences in survival. Multivariate analysis was performed using the Cox proportional hazards model selected in forward stepwise. A P-value of $<0.05$ was considered to indicate a statistically significant result.

\section{Results}

Ezrin is co-expressed with CD44 in CSCs. CSCs $\left(10^{6}\right)$ were sorted from the MDA-MB-231 cell line, and the serum-free suspension was cultured. After 6 days of culture, single-cell suspensions of CSCs separated from the cell line produced viable mammospheres $(20-100 \mu \mathrm{m})$, which could be passaged further. Double immunofluorescence staining showed that the Ezrin protein was co-expressed with CD44 in CSCs. Moreover, the co-immunoprecipitation test also showed that the Ezrin protein was co-precipitated with the CD44 protein (Fig. 1).

Downregulation of Ezrin protein level by siRNA. By replacing the serum culture medium at $6 \mathrm{~h}$ after siRNA transfection, we observed that the successfully transfected CSCs appeared as green fluorescence using fluorescence microscopy. The positive rate of transfected cells was $66.12 \pm 18.46 \%$ in the CSCs. The expression of Ezrin was examined by western blotting at $48 \mathrm{~h}$ after siRNA transfection (Fig. 1). Efficiency reached $>85 \%$ at the protein level in CSCs.

Ezrin downregulation sensitizes CSCs to chemotherapy drugs. To investigate whether downregulation of Ezrin expression has the potential to sensitize CSCs to chemotherapy, a combination treatment of Ezrin-specific siRNA with chemotherapy drugs was performed. Twenty-four hours after transfection with siRNA, cells were treated with DDP, EPI and DTX at concen-
A

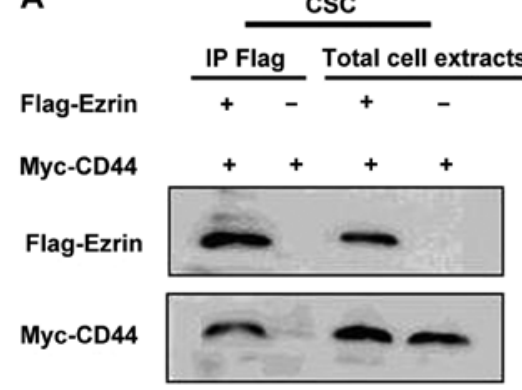

B

Figure 1. Co-immunoprecipitation test indicates that (A) Ezrin protein was co-precipitated with the CD44 protein, and (B) Ezrin was downregulated at $48 \mathrm{~h}$ after siRNA transfection.

trations of $0,0.05,0.1,0.25,0.3,0.35$ and $0.4 \mathrm{mM}$ for $48 \mathrm{~h}$. The $\mathrm{IC}_{50}$ value was determined by CCK-8 assay. The cells exposed to the Ezrin siRNA showed a significant decrease in $\mathrm{IC}_{50}$ for the 3 drugs compared with the control siRNA (P<0.05, Fig. 2).

Expression status of Ezrin and CD44 and the relationship between their co-expression and clinicopathological characteristics. Immunohistochemical examination showed that Ezrin and CD44 were localized in the membrane ruffles and cytoplasm (Fig. 3). The majority of patients $(71.35 \%, 518 / 726)$ were Ezrin-positive in the cytoplasm and membrane; half of the patients $(52.20 \%, 379 / 726)$ were CD44-positive, predominantly in the cytoplasm. It was observed that the Ezrin protein expression was correlated with CD44 expression $(r=0.285$, $\mathrm{P}<0.001)$.

Double immunofluorescence staining showed that Ezrin and CD44 were co-expressed in several cases (Fig. 4). Of the 726 enrolled cases, $235(32.37 \%)$ were determined as co-expressing Ezrin and CD44 protein (Table I). Univariate analysis showed that tumor size, histological type, lymph node metastasis, triple-negative breast cancer, TNM stage, and distant metastasis were observed to be related to Ezrin and CD44 protein co-expression $(\mathrm{P}=0.001,0.001,0.001,0.001$, 0.027 and 0.001 , respectively; Table I). Spearman's correlation analysis showed that Ezrin and CD44 protein co-expression had a linear correlation with tumor size, histological type, lymph node metastasis, triple-negative breast cancer, TNM stage, and distant metastasis $(\mathrm{P}=0.001,0.001,0.001,0.001,0.010$ and
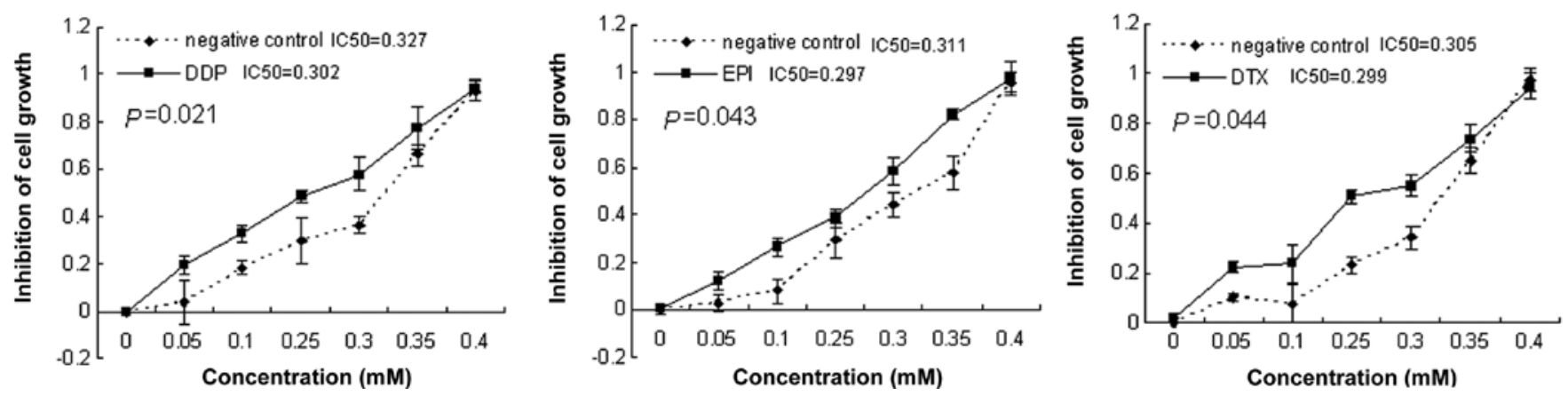

Figure 2. Growth inhibition of cells treated with free DDP, EPI or DTX for $48 \mathrm{~h}$, was evaluated by the CCK- 8 assay and was expressed as a percentage of the untreated cells. Data are reported as the means of 3 independent experiments \pm SD. P-value was compared for the $\mathrm{IC}_{50}$ value between the 2 groups. DDP, cisplatin; EPI, epirubicin; DTX, docetaxel. 


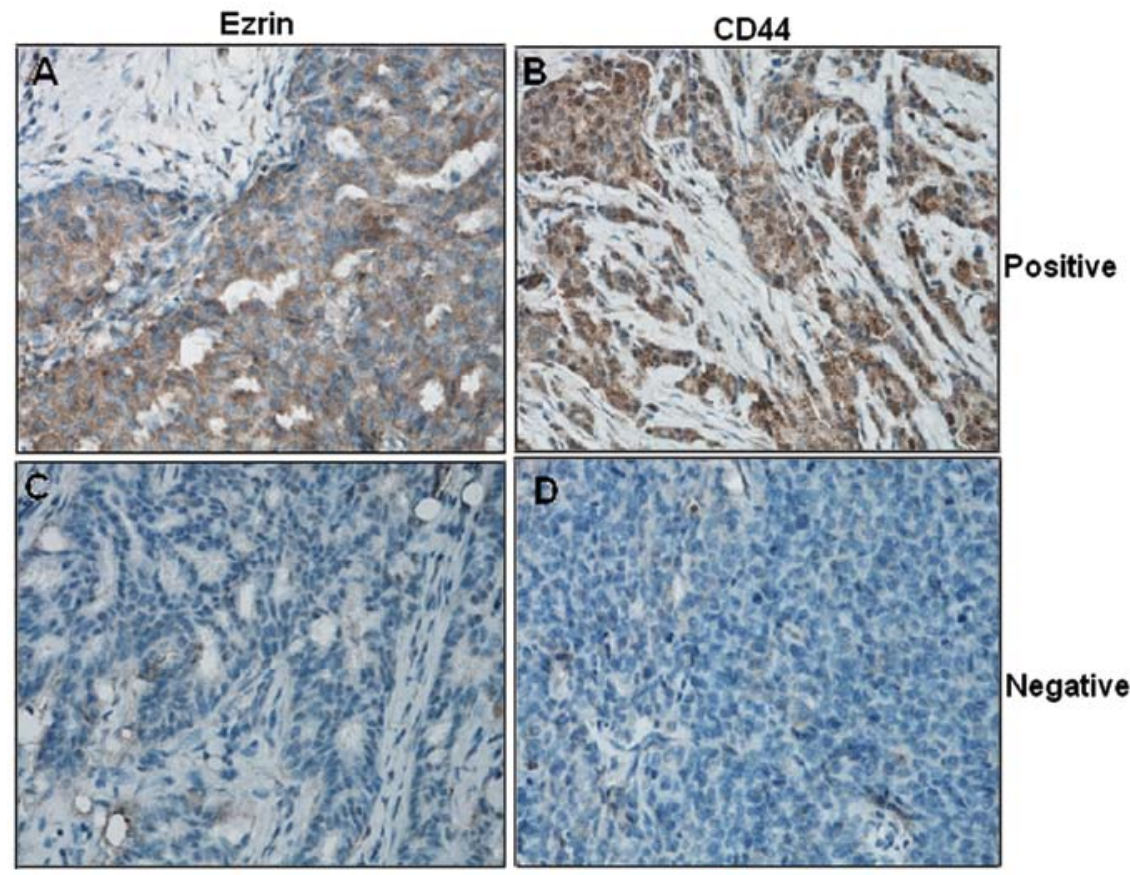

Figure 3. Immunohistochemical examination showed positive and negative expression of Ezrin (A and C) and CD44 (B and D).
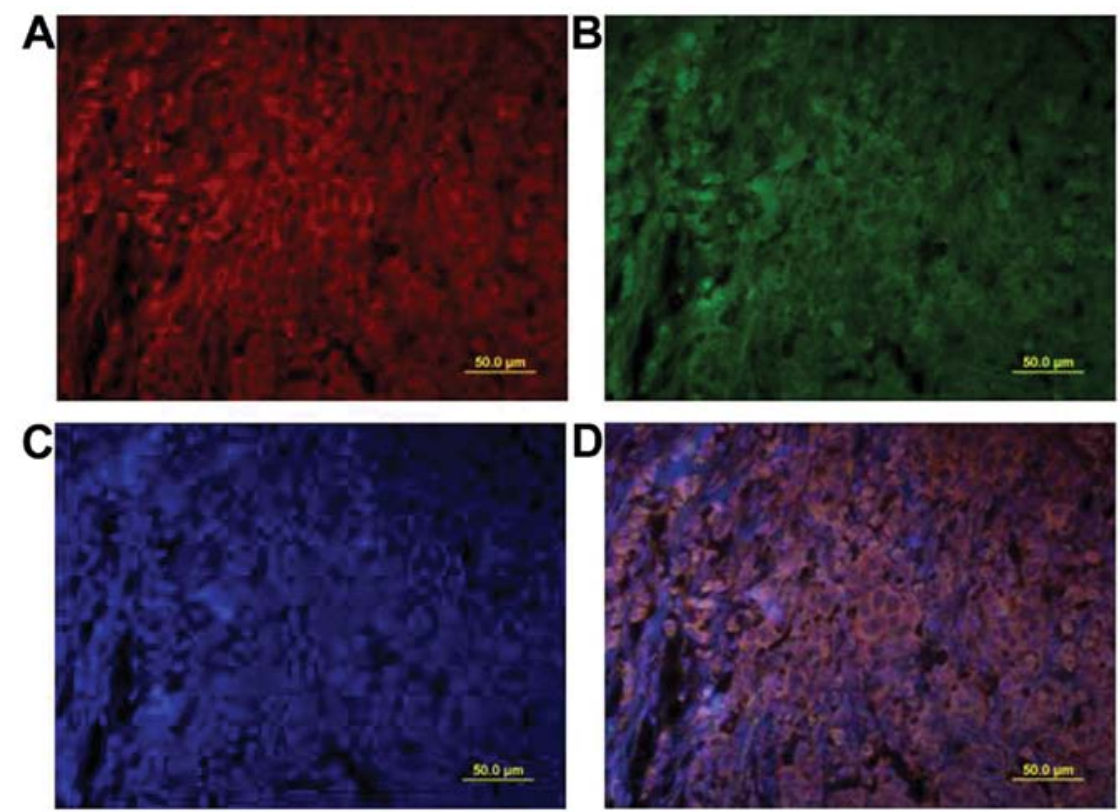

Figure 4. Double immunofluorescence staining indicates that Ezrin and CD44 are co-expressed in breast cancer cases. (A) Rabbit anti-human Ezrin antibody with FITC-conjugated secondary antibody. (B) Rabbit anti-human CD44 antibody with APC-conjugated secondary antibody. (C) DAPI was used to detect nuclei. (D) An overlay of A, B and C is shown. Scale bar, $50 \mu \mathrm{m}$.

0.001, respectively; Table II). Finally, multivariate analysis showed that histological type, lymph node metastasis, triplenegative breast cancer, TNM stage and distant metastasis were related to Ezrin and CD44 co-expression $(\mathrm{P}=0.011,0.006$, $0.001,0.011$ and 0.001 , respectively; Table III).

Association between Ezrin and CD44 protein co-expression and chemotherapeutic resistance. In the present study, patients exhibiting Ezrin and CD44 protein co-expression exhibited a significantly higher distant metastasis rate. Of the 235 cases with Ezrin and CD44 protein co-expression, 115 (48.94\%) developed 5-year, post-operative distant metastasis, whereas only 88 (17.92\%) of cases without Ezrin and CD44 protein co-expression developed 5-year post-operative distant metastasis $(\mathrm{P}=0.001)$.

We further studied the relationship between Ezrin and CD44 protein co-expression and chemotherapeutic sensitivity in 102 breast cancer cases with neoadjuvant chemotherapy. 
Table I. Relationship between Ezrin and CD44 co-expression and clinicopathological factors $(n=726)$.

\begin{tabular}{|c|c|c|c|c|}
\hline Characteristics & $\mathrm{n}$ & Ezrin $^{+} / \mathrm{CD} 44^{+}$ & $\chi^{2}$ & P-value \\
\hline Age (years) & & & 0.012 & 0.914 \\
\hline$\leq 35$ & 122 & 40 & & \\
\hline$>35$ & 604 & 195 & & \\
\hline Tumor size & & & 18.881 & 0.001 \\
\hline $\mathrm{T} 1$ & 131 & 61 & & \\
\hline $\mathrm{T} 2$ & 550 & 167 & & \\
\hline $\mathrm{T} 3$ & 45 & 7 & & \\
\hline Histological type & & & 33.848 & 0.001 \\
\hline I & 50 & 10 & & \\
\hline II & 484 & 131 & & \\
\hline III & 192 & 94 & & \\
\hline Lymph node metastasis & & & 33.992 & 0.001 \\
\hline Positive & 353 & 151 & & \\
\hline Negative & 373 & 84 & & \\
\hline $\begin{array}{l}\text { Triple-negative } \\
\text { breast cancer }\end{array}$ & & & 17.855 & 0.001 \\
\hline Yes & 182 & 82 & & \\
\hline No & 544 & 153 & & \\
\hline TNM stage & & & 7.221 & 0.027 \\
\hline I & 48 & 13 & & \\
\hline II & 517 & 156 & & \\
\hline III & 161 & 66 & & \\
\hline Distant metastasis & & & 174.430 & 0.001 \\
\hline Negative & 524 & 95 & & \\
\hline Positive & 202 & 140 & & \\
\hline
\end{tabular}

Table II. Spearman's correlation analysis between clinicopathological features, and Ezrin and CD44 protein co-expression.

\begin{tabular}{lc}
\hline $\begin{array}{l}\text { Clinicopathological } \\
\text { features }\end{array}$ & $\begin{array}{c}\text { Ezrin and CD44 co-expression } \\
\text { P-value (Spearman's correlation) }\end{array}$ \\
\hline Age & $0.914(0.004)$ \\
Tumor size & $0.001(0.161)$ \\
Histological type & $0.001(0.211)$ \\
Lymph node metastasis & $0.001(0.216)$ \\
Triple-negative breast cancer & $0.001(0.096)$ \\
TNM stage & $0.010(0.074)$ \\
Distant metastasis & $0.001(0.490)$ \\
\hline
\end{tabular}

Ezrin and CD44 protein were co-expressed in 16.67, 27.66, 37.50 and $63.16 \%$ of patients with complete response, partial response, stable disease, and progressive disease $(\mathrm{P}=0.024)$, respectively (Table IV).

Prognostic analysis. In the prognostic analysis, Ezrin and CD44 protein co-expression along with age, histological type, lymph node metastasis, TNM stage, triple-negative breast
Table III. Multivariate analysis of the factors related to Ezrin and CD44 co-expression.

\begin{tabular}{lrcc}
\hline Characteristics & OR & 95\% CI for OR & P-value \\
\hline Age & 1.449 & $0.861-2.438$ & 0.163 \\
Tumor size & 0.684 & $0.425-1.102$ & 0.494 \\
Histological type & 1.603 & $1.114-2.307$ & 0.011 \\
Lymph node metastasis & 1.664 & $1.009-2.744$ & 0.006 \\
Triple-negative & 0.367 & $0.229-0.587$ & 0.001 \\
breast cancer & & & \\
TNM stage & 0.743 & $0.440-1.253$ & 0.011 \\
Distant metastasis & 13.023 & $7.935-21.371$ & 0.001 \\
\hline
\end{tabular}

CI, confidence interval.

Table IV. Correlations between Ezrin and CD44 protein coexpression and chemotherapeutic resistance of breast cancers $[\mathrm{n}=102 ; \mathrm{n}(\%)]$.

\begin{tabular}{lrrrr}
\hline Response & $\mathrm{n}$ & Ezrin $^{+} / \mathrm{CD} 44^{+}$ & $\chi^{2}$ value & P-value \\
\hline Complete response & 12 & $2(16.67)$ & 9.533 & 0.024 \\
Partial response & 47 & $13(27.66)$ & & \\
Stable disease & 24 & $9(37.50)$ & & \\
Progressive disease & 19 & $12(63.16)$ & & \\
\hline
\end{tabular}

Table V. Cox model regression analysis of the breast cancer prognostic factors.

\begin{tabular}{lccc}
\hline Characteristics & OR & 95\% CI for OR & P-value \\
\hline Age & 0.512 & $0.353-0.741$ & 0.001 \\
Tumor size & 0.659 & $0.452-0.960$ & 0.030 \\
Histological type & 0.737 & $0.513-1.059$ & 0.099 \\
Lymph node metastasis & 2.007 & $1.215-3.314$ & 0.006 \\
Triple-negative & 1.315 & $1.117-1.622$ & 0.010 \\
breast cancer & & & \\
TNM stage & 1.866 & $1.156-3.011$ & 0.011 \\
Distant metastasis & 1.962 & $1.357-2.601$ & 0.007 \\
Ezrin and CD44 & 0.680 & $0.484-0.958$ & 0.027 \\
co-expression & & & \\
\hline
\end{tabular}

CI, confidence interval.

cancer, and distant metastasis were shown to be associated with a poor disease-specific survival $(\mathrm{P}=0.001,0.035,0.001$, 0.010, 0.001, 0.001 and 0.001, respectively; Fig. 5). In the Cox regression test, age, tumor size, lymph node metastasis, triplenegative breast cancer, TNM stage, distant metastasis, and Ezrin, and CD44 co-expression was detected as independent prognostic factors $(\mathrm{P}=0.001,0.030,0.006,0.010,0.011,0.007$ and 0.027 , respectively; Table V). 

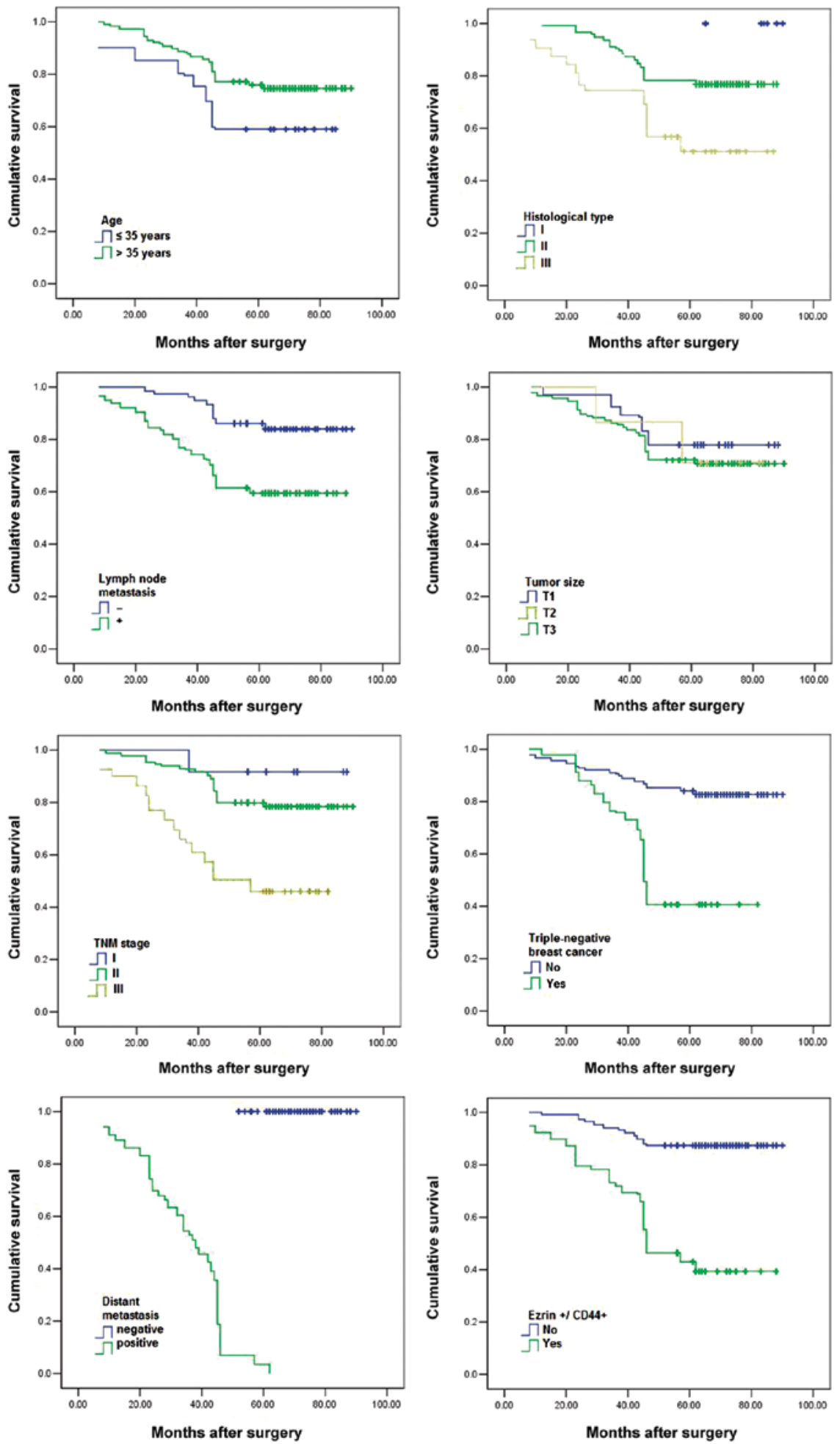

Figure 5. Age, histological type, lymph node metastasis, tumor size, TNM stage, triple-negative breast cancer, distant metastasis, and Ezrin/CD44 co-expression were shown to be correlated with patient prognosis $(\mathrm{P}=0.001,0.035,0.001,0.010,0.001,0.001$ and 0.001 , respectively).

\section{Discussion}

Recently, studies have confirmed that tumor stem cells are the cells that initiate tumors and cause malignant tumor drug resistance, relapse and metastasis $(13,14)$. Hence, it is important to explore the key factors that regulate the self-renewal and multipotentiality of tumor cells, and show that unregulated cell growth is due to disruptions in the regulatory mechanism of stem cell renewal. Currently, the studies addressing the function and specific mechanism of stem cell-related genes in the biological behavior of breast cancer are still sparse (15). In 2003, Al-Hajj et al (5) first sorted and identified $\mathrm{CD}_{4} 4^{+} / \mathrm{CD} 24^{-/ l o w} /$ Lineage tumor cells, which showed higher tumorigenicity and cell microsphere ability than other groups of cells. This greatly encouraged us to further explore the characteristics of breast cancer stem 
cells to discover new methods of clinical treatment. Little is known, however, about the relationship between the expression of stem cell-related genes and the clinicopathological features of breast cancer.

Ezrin is a protein that is encoded by the EZR gene in humans (16). As a member of the ERM protein family, Ezrin works as an intermediary between the plasma membrane and the actin cytoskeleton. CD44, the breast cancer CSC marker, receives its anchor function by connecting to the cytoskeleton via the Ezrin-Radixin-Moesin protein family (17). It has been reported to play a key role in cell surface structure adhesion, migration and organization. Ezrin has been shown to interact with CD44 in osteosarcoma, salivary gland adenoid cystic carcinoma, and in hematological neoplasias $(18,19)$. The status of Ezrin protein expression in breast CSCs and breast cancer, however, is currently unknown. Moreover, the clinical implications of Ezrin and CD44 co-expression in breast cancer are also unclear.

In the present study, we selected and identified breast cancer stem cells based on clinical specimens. It was found that Ezrin and CD44 were co-expressed in CSC tumor cells and were related to $\mathrm{CSC}$ chemotherapy resistance. We further investigated the clinical implications of Ezrin and CD44 expression in breast cancer. Of the 726 breast cancer cases examined in the present study, Ezrin and CD44 co-expression was observed in $32.37 \%$ of cases. After universal and multivariate analysis, histological type, lymph node metastasis, triple-negative breast cancer, TNM stage, and distant metastasis were verified as correlated with Ezrin and CD44 co-expression. Survival analysis revealed that Ezrin and CD44 co-expression was also associated with poorer prognosis. Finally, with Cox regression, Ezrin and CD44 co-expression was shown to be independent prognostic factors of breast cancer.

In conclusion, Ezrin and CD44 co-expression was highly expressed in CSCs and may be a potential biomarker for initiation, progression and differentiation of breast cancer tumors. The underlying genetic mechanism of Ezrin and CD44 co-expression in breast cancer stem cells, however, remains unclear. Hence, the relationship between Ezrin gene expression and the biological behavior of breast cancer stem cells requires further investigation.

\section{Acknowledgements}

The study was funded by the China National Natural Science Foundation.

\section{References}

1. Dowling EC, Klabunde C, Patnick J and Ballard-Barbash R: International Cancer Screening Network (ICSN): Breast and cervical cancer screening programme implementation in 16 countries. J Med Screen 17: 139-146, 2010.
2. Tsuji W, Teramukai S, Ueno M, Toi M and Inamoto T: Prognostic factors for survival after first recurrence in breast cancer: a retrospective analysis of 252 recurrent cases at a single institution. Breast Cancer: Apr 5, 2012 (Epub ahead of print).

3. Magee JA, Piskounova E and Morrison SJ: Cancer stem cells: impact, heterogeneity, and uncertainty. Cancer Cell 21: 283-296, 2012.

4. Liu C, Cao X, Zhang Y, Xu H, Zhang R, Wu Y, Lu P and Jin F: Co-expression of Oct- 4 and Nestin in human breast cancers. Mol Biol Rep 39: 5875-5881, 2012.

5. Al-Hajj M, Wicha MS, Benito-Hernandez A, Morrison SJ and Clarke MF: Prospective identification of tumorigenic breast cancer cells. Proc Natl Acad Sci USA 100: 3983-3988, 2003.

6. Louderbough JM and Schroeder JA: Understanding the dual nature of CD44 in breast cancer progression. Mol Cancer Res 9: 1573-1586, 2011.

7. Ren L, Hong SH, Chen QR, Briggs J, Cassavaugh J, Srinivasan S, Lizardo MM, Mendoza A, Xia AY, Avadhani N, et al: Dysregulation of ezrin phosphorylation prevents metastasis and alters cellular metabolism in osteosarcoma. Cancer Res 72: 1001-1012, 2012.

8. Bulut G, Hong SH, Chen K, Beauchamp EM, Rahim S, Kosturko GW, Glasgow E, Dakshanamurthy S, Lee HS, Daar I, et al: Small molecule inhibitors of ezrin inhibit the invasive phenotype of osteosarcoma cells. Oncogene 31: 269-281, 2012.

9. Boldrini E, Peres SV, Morini S and de Camargo B: Immunoexpression of Ezrin and CD44 in patients with osteosarcoma. J Pediatr Hematol Oncol 32: e213-e217, 2010.

10. Dontu G, Abdallah WM, Foley JM, Jackson KW, Clarke MF, Kawamura MJ and Wicha MS: In vitro propagation and transcriptional profiling of human mammary stem/progenitor cells. Genes Dev 17: 1253-1270, 2003.

11. Liu W, Rui H, Wang J, Lin S, He Y, Chen M, Li Q, Ye Z, Zhang S, Chan SC, et al: Axin is a scaffold protein in TGF- $\beta$ signaling that promotes degradation of Smad7 by Arkadia. EMBO J 25: 1646-1658, 2006 .

12. Remmele W and Stegner HE: Recommendation for uniform definition of an immunoreactive score (IRS) for immunohistochemical estrogen receptor detection (ER-ICA) in breast cancer tissue. Pathologe 8: 138-140, 1987 (in German).

13. Liu S, Clouthier SG and Wicha MS: Role of microRNAs in the regulation of breast cancer stem cells. J Mammary Gland Biol Neoplasia 17: 15-21, 2012

14. Countercurrents Series and Narod SA: A model for breast cancer risk based on stem-cell theory. Curr Oncol 19: 9-11, 2012.

15. Liu CG, Lu Y, Wang BB, Zhang YJ, Zhang RS, Lu Y, Chen B, $\mathrm{Xu} \mathrm{H}$, Jin F and Lu P: Clinical implications of stem cell gene Oct-4 expression in breast cancer. Ann Surg 253: 1165-1171, 2011.

16. Gould KL, Bretscher A, Esch FS and Hunter T: cDNA cloning and sequencing of the protein-tyrosine kinase substrate, ezrin, reveals homology to band 4.1. EMBO J 8: 4133-4142, 1989.

17. Hart SP, Rossi AG, Haslett C and Dransfield I: Characterization of the effects of cross-linking of macrophage CD44 associated with increased phagocytosis of apoptotic PMN. PLoS One 7: e33142, 2012.

18. Wang YY, Chen WL, Huang ZQ, Yang ZH, Zhang B, Wang JG, Li HG and Li JS: Expression of the membrane-cytoskeletal linker Ezrin in salivary gland adenoid cystic carcinoma. Oral Surg Oral Med Oral Pathol Oral Radiol Endod 112: 96-104, 2011.

19. Hertweck MK, Erdfelder F and Kreuzer KA: CD44 in hematological neoplasias. Ann Hematol 90: 493-508, 2011. 